\title{
Finite Element Analysis of Steel Elliptical Hollow Section Column
}

\author{
S.Nithiyaasri ${ }^{1}$, Dr.A.Leema Rose ${ }^{2}$, M.Saranya ${ }^{3}$ \\ PG Student ${ }^{1}$ Associate Professor ${ }^{2}$, Assistant Professor ${ }^{3}$ \\ Department of Civil Engineering, Valliammai Engineering College, Kattankulathur, Kanchipuram District, Tamilnadu,

$$
\text { India }^{1,2,3}
$$

\begin{abstract}
The structural hollow section rectangular, square, circular used in the steel construction will not simultaneously satisfy both the architectural and structural point of view. To overcome this constraint, Elliptical hollow section is the new shape introduced in the structural hollow section. Elliptical hollow section column in the steel construction is to have attention from architects and structural engineers. The elliptical hollow column section properties are taken from the codes EN 10210-2-2006, EN 10219-2-2006. The major axis used in the elliptical hollow section is $150,180,300,400 \mathrm{~mm}$ and the minor axis is $75,90,150,200 \mathrm{~mm}$. The thickness of $2 \mathrm{~mm}$. The aspect ratio is of 2. This performance of the class 4 limit according to the euro code 3 elliptical section column by finite element software (using Abaqus software) under axial loading is determined. The critical load calculation by Rankine's formula was also adopted in this study. The critical loads obtained from Abaqus software analysis and from Rankine's formula are compared.
\end{abstract}

Keywords: Elliptical hollow section column, Rankine's formula, Euro code 3, finite element analysis

\section{INTRODUCTION}

The elliptical hollow section is a type of hollow structural rolling. This process will produce steel with closer section that is relatively new shape to the steel dimensional tolerances and a wider range of surface construction. The use of Hollow steel section is more finishes. The term Cold Rolled is mistakenly used on all efficient as compression member than any other structural products, when actually the product name refers to the steel section e.g. I, H, L sections due to their geometry rolling of flat rolled sheet and coil products.

shape. The elliptical hollow section is made in such a manner to obtain technically secure, economic and $\mathrm{C}$. architecturally pleasing structure in both architect and design engineer point of view. Elliptical hollow section will be more effective for using in the highly wind exposed structures because of its shape it reduces the loading. Elliptical hollow section column strength will be more than the open section due to its higher moment of inertia. Elliptical hollow section has a structural efficiency due to its different major and minor axis. Elliptical hollow section will be more suitable for limited space structure due its shape. The cold formed elliptical hollow section steel column is analysed by both numerical simulation in finite element Abaqus software and experimental testing.

A. Objective

- To determine the behaviour of elliptical hollow section column under the compression loading.

- To determine the strength and stability of the elliptical hollow section column.

\section{B. Cold Formed Steel}

Cold rolled steel is essentially hot rolled steel that has had further processing. The steel is processed further in cold reduction mills, where the material is cooled (at room temperature) followed by annealing and/or tempers

\section{Characteristics of Cold Formed Steel}

More finished surfaces with closer tolerances.

Smooth surfaces that are often oily to the touch.

Cold formed steel sections often have welldefined edges and corners.

Tubes have better concentric uniformity and straightness.

- Cold formed steel is often used for more technically precise applications or where aesthetics are important.

- The additional processing for cold finished products, they come at a higher price.

- In terms of their physical characteristics, cold worked treatments can also create internal stresses within the material.

Fabricating cold worked steel-whether by cutting, grinding, or welding it can release tensions and lead to unpredictable warping.

$\begin{array}{ll}\text { D. } & \text { Advantage of Cold Formed Steel } \\ \text { - } & \text { Lightness in weight } \\ \text { - } & \text { High strength and stiffness } \\ \text { - } & \text { Ease of prefabrication and mass production } \\ \text { - } & \text { Substantial elimination of delays due to weather }\end{array}$




\section{International Advanced Research Journal in Science, Engineering and Technology}

\section{ISO 3297:2007 Certified}

Vol. 4, Issue 3, March 2017

- $\quad$ More accurate detailing

- Non shrinking and non-creeping at ambient temperatures

$\begin{array}{ll}\text { - } & \text { No formwork needed } \\ \text { - } & \text { Termite-proof and rot proof } \\ \text { - } & \text { Eniform quality } \\ \text { - } & \text { Nonomy in transportation and handling } \\ \text { - } & \text { Recyclable material } \\ \text { - } & \text { Panels and decks can provide enclosed cells for } \\ \text { conduits }\end{array}$

\section{METHODOLOGY}

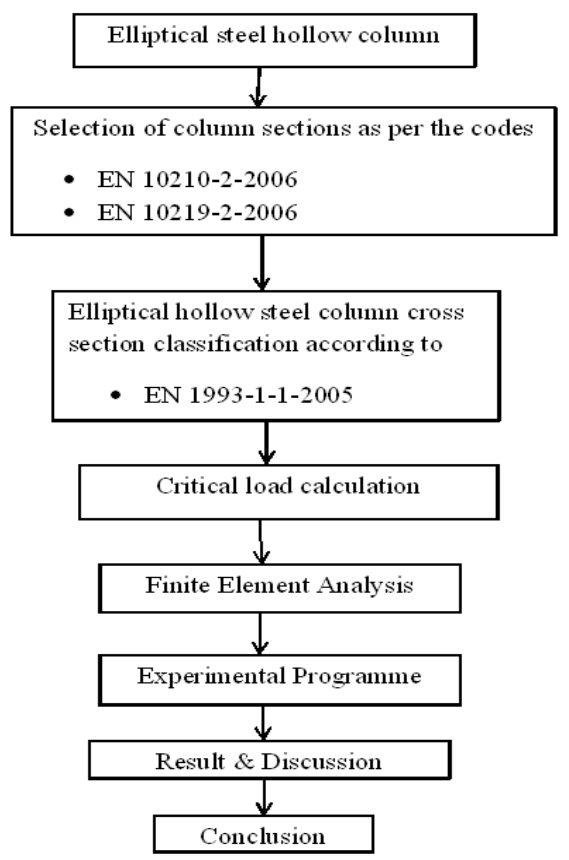

Fig.1 Methodology flowchart

Four cross section of elliptical hollow section columns of $150 \times 75 \mathrm{~mm}$ and $180 \times 90 \mathrm{~mm} \mathrm{300 \times} 150 \times 2 \mathrm{~mm}$ and $400 \times 200 \times 2 \mathrm{~mm}$ were used for both numerical modelling and experimental testing. The cross sections used as per the code EN 10210-2-2006 and EN 10219-2-2006. The thicknesses of the columns are $2 \mathrm{~mm}$. The aspect ratio of the column is 2 for the both cross sections. The height of column is $1200 \mathrm{~mm}$. The cold formed structural steel 235 grade is used. Four elliptical hollow section columns were used for numerical modelling and experimental testing.

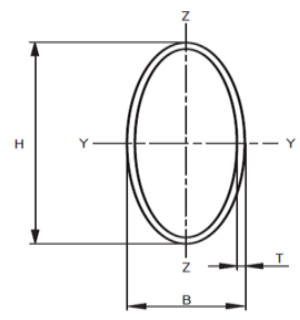

Fig.2 Elliptical Hollow Section

\section{A. classification of column}

In this study four elliptical hollow section

\section{A. Classification of Column}

In this study four elliptical hollow section column $150 \mathrm{x}$ $75 \times 2 \mathrm{~mm}, 180 \times 90 \times 2 \mathrm{~mm}, 300 \times 150 \times 2 \mathrm{~mm}$ and $400 \times 200 \times 2 \mathrm{~mm}$ are used. The classification of column is whether long, intermediate, or short columns. The classification of column is depends on the slenderness ratio. For long column the slenderness ratio is greater than 120. For the intermediate column slenderness ratio is greater 20 and less than 120 . For the short column the slenderness ratio should be less than 20.The effective length of column depends on the boundary conditions of column. Hinged-hinged boundary condition i.e. simply supported end condition is adopted for this study. The elliptical hollow section columns areas of cross section, moment of inertia are calculated by referring the code EN 10219-2-2006.

Area of cross section,A

$\mathrm{A}=\frac{\pi[\mathrm{HB}-(\mathrm{H}-2 \mathrm{~T})(\mathrm{B}-2 \mathrm{~T})]}{4} \quad\left(\mathrm{~mm}^{2}\right)$

Moment of inertia for major axis, $I_{y y}$

$$
I_{y y}=\frac{\pi\left[B H^{3}-(B-2 T)(H-2 T)^{3}\right]}{64} \quad\left(\mathrm{~mm}^{4}\right)
$$

Moment of inertia for minor axis, $I_{z z}$

$$
I_{Z Z}=\frac{\pi\left[\mathrm{HB}^{3}-(\mathrm{H}-2 \mathrm{~T})(\mathrm{B}-2 \mathrm{t})^{3}\right]}{64} \quad\left(\mathrm{~mm}^{4}\right)
$$

Radius of gyration $r=\sqrt{\frac{\mathrm{I}}{\mathbf{S}}} \quad(\mathrm{mm})$

Slenderness ratio $\quad \mathrm{K}=\frac{\text { Effective length }}{\text { Radius of gyration }}$

The four elliptical hollow section column area of cross section, moment of inertia, radius of gyration and slenderness ratio are given in the below table 3.1 according to the formulae in code EN 10219-2-2006. The four elliptical hollow section column slenderness ratios are greater than 40 . The elliptical hollow section columns used $150 \times 75 \times 2 \mathrm{~mm}, 180 \times 90 \times 2 \mathrm{~mm}, 300 \times 150 \times 2 \mathrm{~mm}$ and $400 \times 200 \times 2 \mathrm{~mm}$ are intermediate columns.

TABLE 1 DETAIL OF ELLIPTICAL HOLLOW SECTION

\begin{tabular}{|c|c|l|l|l|}
\hline $\begin{array}{c}\text { Column } \\
\text { Section } \\
(\mathbf{m m})\end{array}$ & $\begin{array}{c}\text { Area of } \\
\text { Cross } \\
\text { section } \\
\left(\mathbf{m m}^{2}\right)\end{array}$ & $\begin{array}{c}\text { Moment of } \\
\text { inertia } \\
\left(\mathbf{m m}^{\mathbf{4}}\right)\end{array}$ & $\begin{array}{c}\text { Radius } \\
\text { of } \\
\text { gyration } \\
(\mathbf{m m})\end{array}$ & $\begin{array}{c}\text { Slenderness } \\
\text { ratio }\end{array}$ \\
\hline $150 \times 75 \times 2$ & 694.29 & $5.41 \times 10^{5}$ & 27.92 & 36.75 \\
\hline $180 \times 90 \times 2$ & 835.66 & $9.46 \times 10^{5}$ & 26.79 & 30.36 \\
\hline $300 \times 150 \times 2$ & 1401.15 & $4.482 \times 10^{6}$ & 56.55 & 25.21 \\
\hline $400 \times 200 \times 2$ & 2120.44 & $\begin{array}{l}10.71 \\
10^{6}\end{array}$ & 62.33 & 23.45 \\
& & & & \\
\hline
\end{tabular}




\section{International Advanced Research Journal in Science, Engineering and Technology}

\section{ISO 3297:2007 Certified}

Vol. 4, Issue 3, March 2017

\section{B. Cross Section Classification}

The role of cross section classification is to identify the extent to which the resistance of cross sections is limited by its local buckling resistance. Four classes of crosssections, namely Class 1 to 4 have been defined with limiting slenderness values. For the special case of elliptical hollow sections with the slenderness limits for circular hollow sections in Euro code 3 has been achieved. Four classes of cross-sections a

- $\quad$ Class 1 cross-sections are those which can form a plastic hinge with the rotation capacity required from plastic analysis without reduction of the resistance.

- Class 2 cross-sections arc those which can develop their plastic moment resistance, but have limited rotation capacity because of local buckling.

- Class 3 cross-sections are those in which the stress in the extreme compression fibre of the steel member assuming an elastic distribution of stresses can reach the yield strength, but local buckling is liable to prevent development of the plastic moment resistance.

- Class 4 cross-sections are those in which local buckling will occur before the attainment of yield stress in one or parts of the cross-section.

Local buckling is based on the concept of cross section classification. Classification is made by comparing the slenderness of the cross section with the prescribed limits specified in code. Elliptical hollow section steel column is new to the construction industry, so there is no any specified slenderness parameters in any code of practice. According to the L.Gardner and T.M Chan [2] that circular hollow section class slenderness limit from EN 1993-1-1-2005 will be suitable for the elliptical hollow section steel column. Cross section classification limits for the circular hollow section are adopted for the elliptical hollow section.

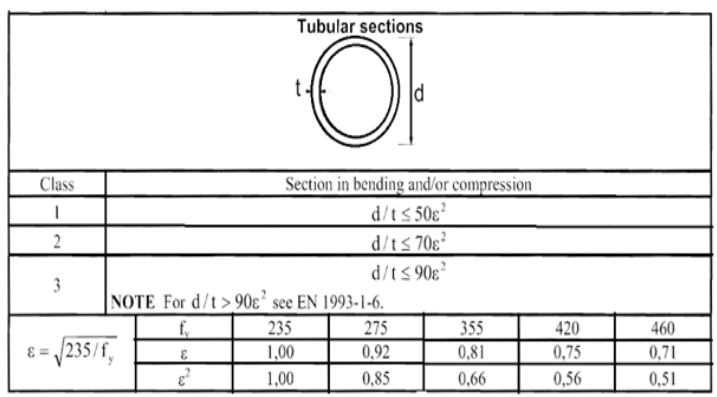

Fig. 3 Maximum width-to-thickness ratios for compression parts- CHS

The cross section classification limits for the class will be according to the maximum width to thickness for the circular hollow section. For the elliptical hollow section, the cross-section slenderness parameter given by Gardner and Chan [2]:

$$
\frac{D_{\mathrm{e}}}{\mathrm{t} \varepsilon^{2}}=\frac{2\left(a^{2} / b\right)}{\mathrm{t} \varepsilon^{2}}
$$

Where allow $\mathrm{D}_{\mathrm{e}}$ is the equivalent diameter and $\varepsilon^{2}=\frac{235}{f_{y}}$ for a range of yield strengths. It has been proposed that the equivalent diameter De be based upon the point along the circumference of an ellipse at which local buckling initiates this point corresponds to the maximum radius of curvature

$\left(r_{\max }=\mathrm{a}^{2} / \mathrm{b}\right)$ which occurs at the end of the major axis of the cross-section.

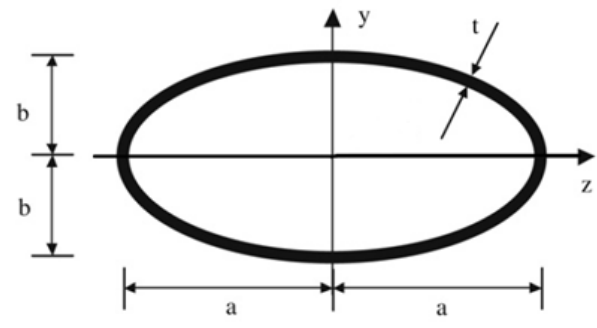

Fig. 4 cross section of EHS

The elliptical hollow section is with referring the maximum width to thickness ratio for the circular hollow section compact and semi compact limits. The elliptical hollow section equivalent diameter to thickness is compared with the maximum width to thickness of circular hollow section. In this study four elliptical hollow section column are chosen, cross section classification for the four EHS column is specified in the below table 2 .

TABLE 2 CROSS SECTION CLASSIFICATIONS

\begin{tabular}{|l|l|l|l|}
\hline Column section & $\frac{\mathbf{D}_{\mathbf{e}}}{\mathbf{t} \boldsymbol{\varepsilon}^{2}}$ & $\begin{array}{l}\text { Limiting } \\
\text { value }\end{array}$ & $\begin{array}{l}\text { Cross section } \\
\text { classification }\end{array}$ \\
\hline $150 \times 75 \times 2 \mathrm{~mm}$ & 150 & $<90$ & Class-4 \\
\hline $180 \times 90 \times 2 \mathrm{~mm}$ & 180 & $<90$ & Class-4 \\
\hline $300 \times 150 \times 2 \mathrm{~mm}$ & 300 & $<90$ & Class-4 \\
\hline $400 \times 200 \times 2 \mathrm{~mm}$ & 400 & $<90$ & Class-4 \\
\hline
\end{tabular}

B.

\section{Critical Load Calculation}

The critical load of a column is that value of axial force that is just sufficient to keep the bar in a slightly deflected shape. The critical load is the maximum load which a column can bear while staying straight. The column will remain straight for loads less than the critical load. The "critical load" is the greatest load that will not cause lateral deflection (buckling). For loads greater than the critical load, the column will deflect laterally. The critical load puts the column in a state of unstable equilibrium. A load beyond the critical load which causes the column to fails by buckling. As the load is increased beyond the critical load the lateral deflections increase, until it may fail in other modes such as yielding of the material.

For the intermediate columns, critical load calculation is by the Rankine's formula. This IS the empirical formula used for the critical load calculation. 


\section{International Advanced Research Journal in Science, Engineering and Technology \\ ISO 3297:2007 Certified}

Vol. 4, Issue 3, March 2017

\section{Critical Load Calculation by Rankine's Formula}

Rankine's formula is an empirical formula used for the calculation of ultimate load both for short and long columns. Rankin's formula is also known as Rankin Gordon Formula. It gives the ultimate load that column can bear before failure. If column is short, calculated load will be known as crushing load. And load will be buckling or crippling load, in case of long column. This formula only gives the ultimate load, but columns are design on safe load. In order to get safe load, divide ultimate load (Load obtained from Rankin's Formula) with factor of safety.

The material properties were determined by carrying out standardised tensile tests according to IS 16082005.The Poisson's ratio for the used steel is 0.3 and young's modulus is $200 \mathrm{Gpa}$. Yield stress $255 \mathrm{Mpa}$ and ultimate stress of $425 \mathrm{Mpa}$.

$$
\text { Critical load } \mathrm{p}=\frac{\sigma_{\mathrm{c}} \mathrm{A}}{1+\alpha\left(\frac{L_{e}}{\mathrm{k}}\right)^{2}}
$$

Where, $\sigma_{c}-$ ultimate crushing stress for the column material

$$
\begin{aligned}
& \text { A - Cross sectional area of column } \\
& \mathrm{k} \text { - Least radius of gyration } \\
& L_{e} \text { - Effective length of column } \\
& \sigma_{\mathrm{c}} \text { - ultimate stress } \\
& \alpha-\text { Constant. Its value given by } \\
& \alpha=\frac{\sigma_{\mathrm{c}}}{E \pi^{2}} \\
& \mathrm{E}-\text { Young's modulus }
\end{aligned}
$$

The critical load calculation for the four elliptical hollow section columns $150 \times 75 \times 2 \mathrm{~mm}, 180 \times 90 \times 2 \mathrm{~mm}$, $300 \times 150 \times 2 \mathrm{~mm}$ and $400 \times 200 \times 2 \mathrm{~mm}$ their critical load is calculated according to the above Rankine's formula with required data is shown in the table 3

TABLE 3 CRITICAL LOAD ACCORDING TO RANKINE'S FORMULA

\begin{tabular}{|l|l|}
\hline Column section & $\begin{array}{l}\text { Critical load according to } \\
\text { Rankine's Formula }\end{array}$ \\
\hline $150 \times 75 \times 2 \mathrm{~mm}$ & $252.66 \mathrm{KN}$ \\
\hline $180 \times 90 \times 2 \mathrm{~mm}$ & $307.61 \mathrm{KN}$ \\
\hline $300 \times 150 \times 2 \mathrm{~mm}$ & $352.66 \mathrm{KN}$ \\
\hline $400 \times 200 \times 2 \mathrm{~mm}$ & $490.71 \mathrm{KN}$ \\
\hline
\end{tabular}

D.

Finite Element Analysis

Finite element analysis is a computerized method for predicting how a structural component reacts to forces, vibration, heat, fluid flow, and other physical effects. Finite element analysis shows whether a product will break, wear out, or work the way it was designed. It is called analysis, but in the structure development process, it Copyright to IARJSET is used to predict what is going to happen when the structure is used. Finite element analysis is done by preprocessing (finite element modelling) and post processing.

Finite element modelling is also known as pre-processing. Pre-processing is something you do before processing your analysis. Pre-Processing involves the defining the geometry, defining the material properties, and loading, applying boundary conditions and meshing. The post processing stage deals with the representation of results. Typically, the deformed configuration, mode shapes, temperature, and stress distribution are computed and displayed at this stage.

\section{Finite Element Modelling}

In this study, numerical modelling study, using the finite element (FE) software ABAQUS was carried out. The ABAQUS suite of software for finite element analysis (FEA) is known for its high performance, quality and ability to solve more kinds of challenging simulations than any other software. ABAQUS is a software application used for both the modelling and analysis of mechanical components and assemblies (pre-processing) and visualizing the finite element analysis result.

Two elliptical hollow section column models of $300 \times 150$ x $2 \mathrm{~mm}$, and $400 \times 200 \times 2 \mathrm{~mm}$ are designed in the finite element software ABAQUS/CAE, provides a complete modelling and visualization environment for ABAQUS analysis products. With direct access to CAD models, advanced meshing and visualization, and with an exclusive view towards ABAQUS analysis products, ABAQUS/CAE is the modelling environment of choice for many ABAQUS users. In finite element software ABAQUS the columns are analysed by defining the following part, property, assembly, step, load, mesh.

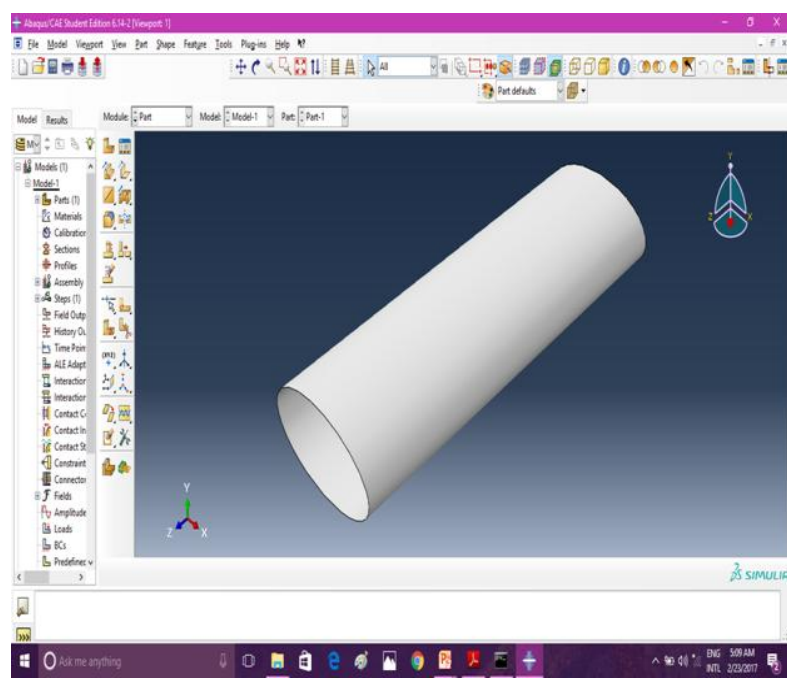

Fig.5 Elliptical Hollow Section Model 400 x 200 x 2mm 


\section{International Advanced Research Journal in Science, Engineering and Technology}

ISO 3297:2007 Certified

Vol. 4, Issue 3, March 2017

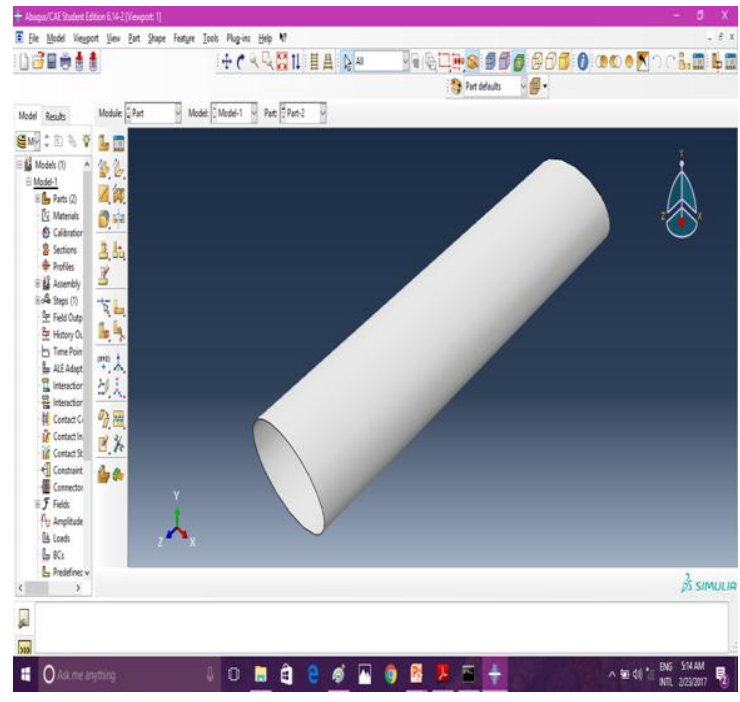

Fig.6 Elliptical Hollow Section Model 300 x 150 x 2mm

\section{Meshing}

Meshing technique is the most easily access able meshing mechanism in Abaqus that requires no pre-established mesh pattering (eg partitioning). The process of meshing a part with complex geometry can be either highly rewarding or, as is more often the case, highly frustrating. Creating a clean, uniform mesh for a structural analysis has gotten easier as meshing algorithms and tools have improved. We are not at point, however, when one can rely entirely on the pre-processor to generate an adequate mesh, particularly for parts that contain odd geometric shapes and curvature. In such cases, the first step to a good mesh is to assist the pre-processor by dividing the geometry into shapes that are more easily processed. The second step is to select the algorithm that is most appropriate for the partitioned geometry. Abaqus/CAE is the finite element analysis software that is used here, but all of the major finite element analysis platforms have tools that can be used with the concepts presented here.

In this study, elliptical hollow section columns $150 \mathrm{x}$ $75 \times x 2 \mathrm{~mm}, \mathrm{x} 180 \times 90 \times 2 \mathrm{~mm} 300 \times 150 \times 2 \mathrm{~mm}, 400 \times 200$ $\mathrm{x} 2 \mathrm{~mm}, \mathrm{~mm}$ are meshed in ABAQUS software. The 720 mesh elements are created for each elliptical hollow section column.

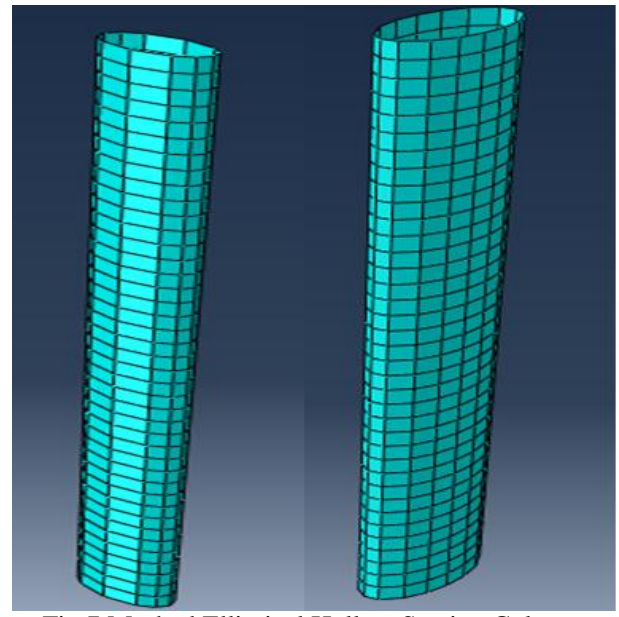

Fig.7 Meshed Elliptical Hollow Section Columns

\section{Post Processing}

Finite element analysis successfully according to the prompt in the log tag of job monitor, you can choose the results button in job manager window to enter visualization module to view the result in different methods. The Visualization module provides graphical display of finite element models and results. It obtains model and result information from the output database; you can control what information is placed in the output database by modifying output requests in the step module i.e. the type of analysis. In this study buckling analysis is requested. After a finite element model has been prepared and checked, boundary conditions have been applied, and the model has been solved, it is time to investigate the results of the analysis. This activity is known as the postprocessing phase of the finite element method.

In the visualization module we can view undeformed shape, deformed shape, Animation of results, Contour plots, Eigenvalue (critical load). In the contour plot we can view deformed shape and un-deformed shape separately and both combined. In the animation of result, the video of section will be shown how the section getting deformed.

Finite element analysis results for the four columns are shown below.

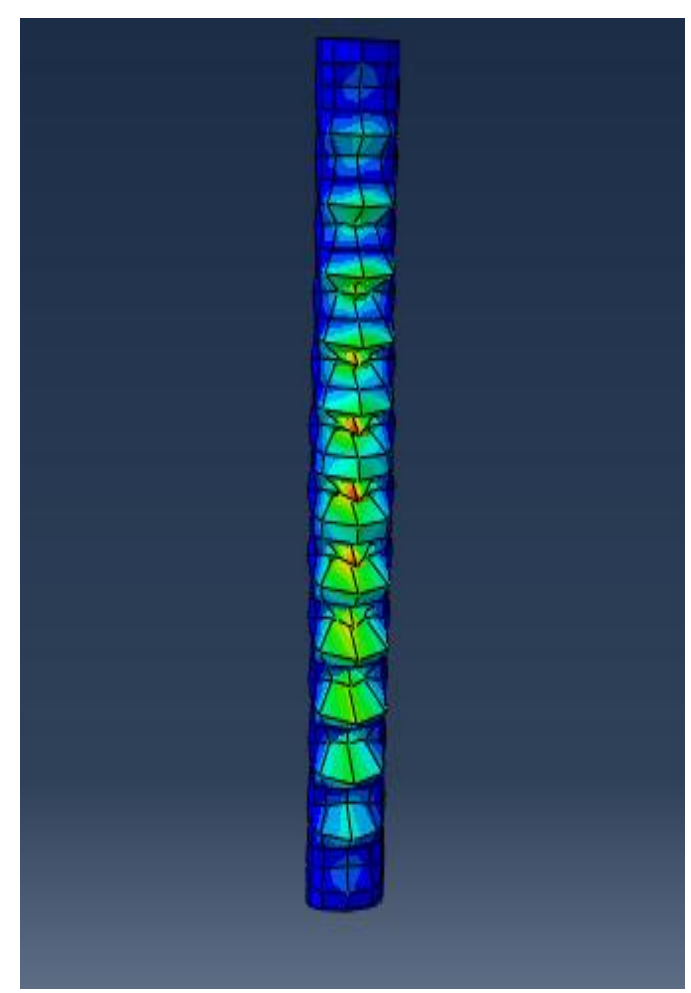

Fig.8 Numerical tested Elliptical Hollow Section Column $150 \times 75 \times 2 \mathrm{~mm}$ 


\section{International Advanced Research Journal in Science, Engineering and Technology}

ISO 3297:2007 Certified

Vol. 4, Issue 3, March 2017

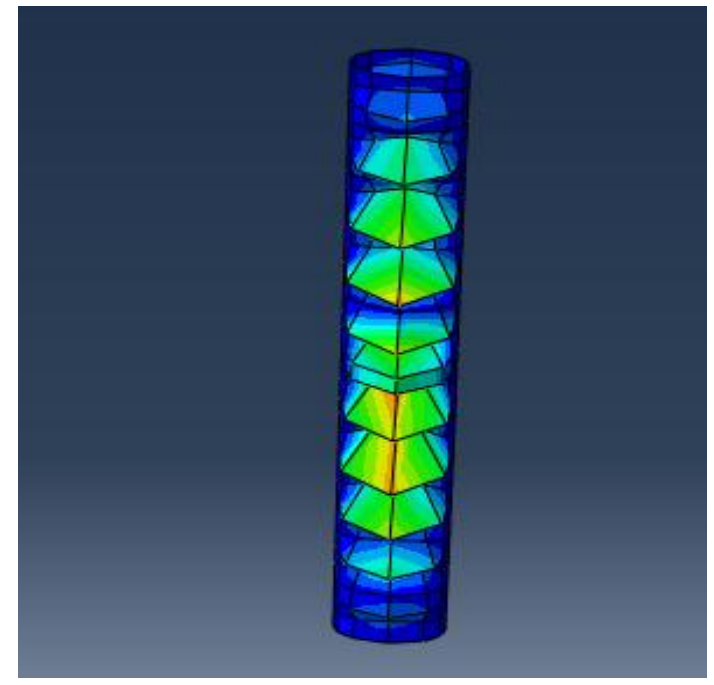

Fig.9 Numerical tested Elliptical Hollow Section Column 180x90x2mm

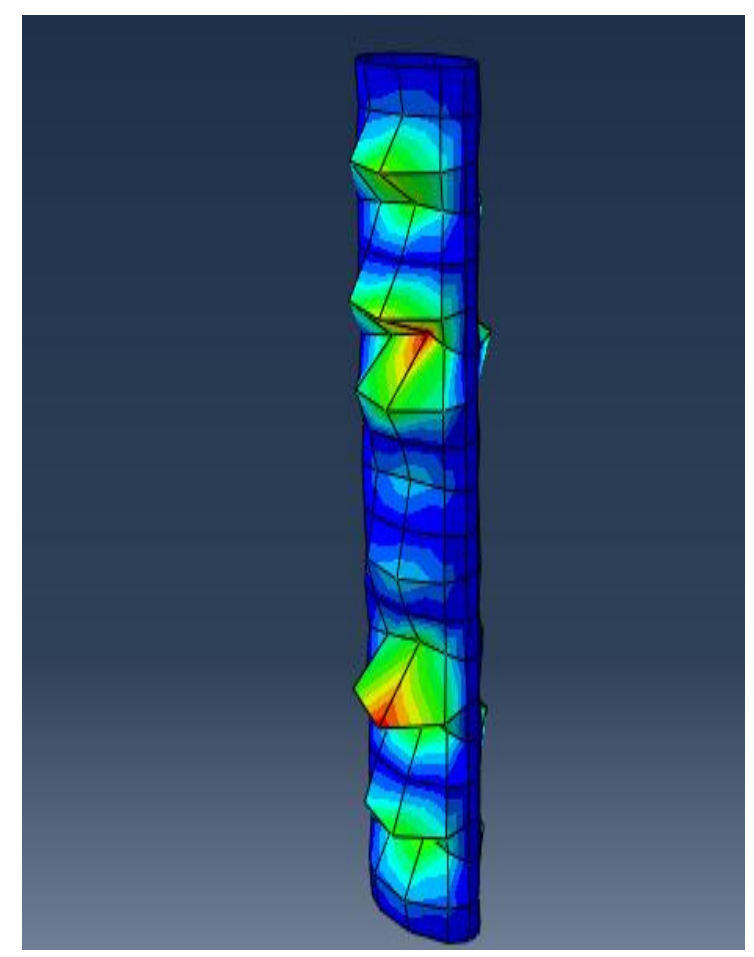

Fig.10 Numerical tested Elliptical Hollow Section Column $300 \times 150 \times 2 \mathrm{~mm}$

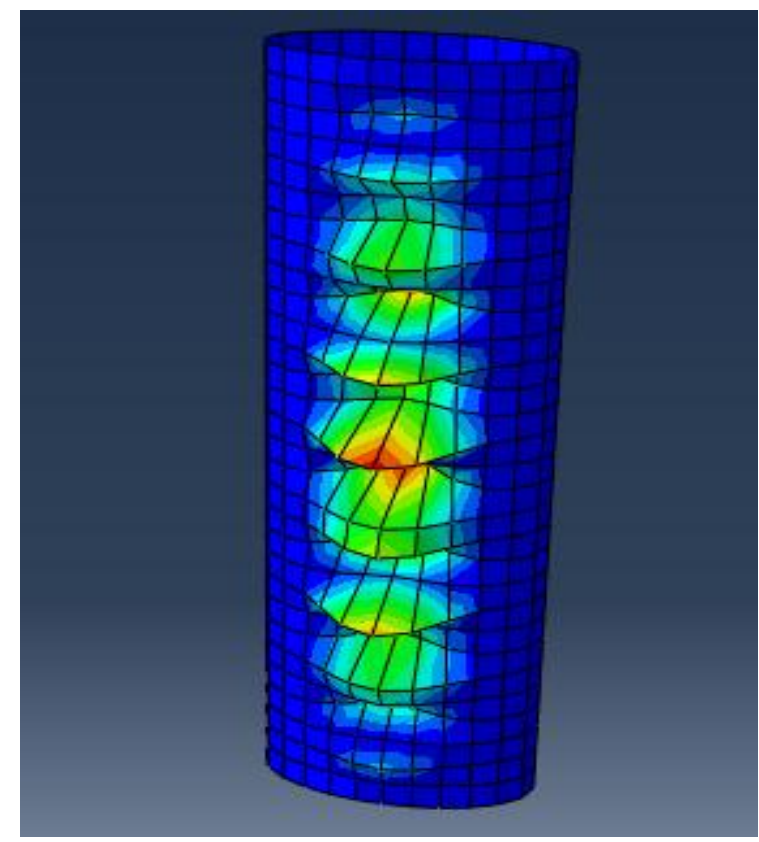

Fig.11 Numerical tested Elliptical Hollow Section Column $400 \times 200 \times 2 \mathrm{~mm}$

\section{RESULT AND DISCUSSION}

\section{A. Error Percentage Analysis}

Error analysis will be for to compare the results of theoretical values or experimental values. This calculation will help to evaluate the relevance of results. In most cases, a percent error or difference of less than $10 \%$ will be acceptable. If the comparison shows a difference of more than $10 \%$, there is a great likelihood that some mistake has occurred, and should look back over lab to find the source of the error. These calculations are also very integral to the analysis and discussion. A high percent error must be accounted for in your analysis of error, and may also indicate that the purpose of the lab has not been accomplished. Percent error is used when are comparing your result to a known or accepted value.

Error percent $=\frac{\text { Experimental value }- \text { theoretical value }}{\text { Experimental value }}$

In the above formula the experimental value indicates the critical load from the finite element analysis and theoretical value indicates the critical load according the Rankine's formula.

TABLE 4 VALIDATION OF FINITE ELEMENT MODEL AGAINST THEORETICAL

\begin{tabular}{|c|c|c|c|}
\hline \multirow{2}{*}{ Column Section } & \multicolumn{2}{|c|}{ Critical Load according to } & \multirow{2}{*}{$\begin{array}{c}\text { Error } \\
(\%)\end{array}$} \\
\hline & $\begin{array}{l}\text { Rankine's } \\
\text { Formula }\end{array}$ & $\begin{array}{l}\text { Finite } \\
\text { Element } \\
\text { Analysis }\end{array}$ & \\
\hline $150 \times 75 \times 2 \mathrm{~mm}$ & $252.66 \mathrm{KN}$ & $263.5 \mathrm{KN}$ & 4.11 \\
\hline $180 \times 90 \times 2 \mathrm{~mm}$ & $307.61 \mathrm{KN}$ & $325.7 \mathrm{KN}$ & 5.5 \\
\hline $300 \times 150 \times 2 \mathrm{~mm}$ & $352.66 \mathrm{KN}$ & $365.5 \mathrm{KN}$ & 3.51 \\
\hline $400 \times 200 \times 2 \mathrm{~mm}$ & $490.71 \mathrm{KN}$ & $509.23 \mathrm{KN}$ & 3.63 \\
\hline
\end{tabular}


The error percentages were found to be less than 10 for all the elliptical hollow section columns. This indicates that the Rankine's formula used and finite element modelling of the elliptical hollow section were found to be same.

\section{CONCLUSION}

This performance study is carried out for the class 4 according to the euro code 3elliptical section column by finite element software (using Abaqus software) under axial loading is determined. The class 4 elliptical hollow section according to the euro code- 3 . The critical load is determined according to by empirical formulae Rankine's theory. Then it is compared with the finite element analysed critical load. It is found that the critical load computed by the above empirical formulae and finite element analysis are to be more or less same. The error percentage has been determined for the elliptical hollow section columns of $150 \times 75 \times 2 \mathrm{~mm}, 180 \times 90 \times 2 \mathrm{~mm}$, $300 \times 150 \times 2 \mathrm{~mm}$ and $400 \times 200 \times 2 \mathrm{~mm}$ were found to be $4.11,5.5,3.51$, and 3.63 respectively. This indicates that the Rankine's formula used and finite element modelling of the class 4 elliptical hollow sections were found to be same.

\section{REFERENCES}

1. F. McCann, C. Fang, L. Gardner, N. Silvestre "Local buckling and ultimate strength of slender elliptical hollow sections in compression" in Engineering Structures 111 (2016) 104-118.

2. T.M. Chan, L. Gardner "Compressive resistance of hot-rolled elliptical hollow sections" in Engineering Structures 30 (2008) 522-532

3. M.Theofanaous, T.M Chan, L. Gardner, "Structural response of stainless steel oval hollow section compression members" in Engineering Structures 31 (2009) 922934

4. Ji-Hua Zhu, Ben Young, Design of cold-formed steel oval hollow section columns in Journal of Constructional Steel Research 71 (2012) 26-37

5. Khwairakpam Sachidananda, Konjengbam Darunkumar Singh Numerical study of fixed ended lean duplex stainless steel (LDSS) flat Oval hollow stub column under pure axial compression in ThinWalled Structures96(2015)105-119.

6. M. Theofanous, L. Gardner Testing and numerical modelling of lean duplex stainless steel hollow section columns in Engineering Structures 31 (2009) 30473058.

7. N. Silvestre, L. Gardner (2011), Elastic Local Post- buckling tubes in Journal of Construction Steel Research in Thin walled structures 46(2008) 1304-1318.

8. A.M. Ruiz-Teran, L. Gardner Elastic buckling of elliptical tubes in Thin-Walled Structures 46 (2008) 1304-1318.

9. J.M. Abela, L.Gardner Elastic buckling of elliptical tubes subjected to generalised linearly varying stress distributions in Thin-Walled Structures58(2012)40-50.

10. M. Theofanous, T.M. Chan, and L.Gardner Flexural behaviour of stainless steel oval hollow sections in Thin-Walled Structures 47(2009)776-787

11. L. Gardner, T.M. Chan and J.M. Abela (2011), Bending strength of hot-rolled elliptical hollow sections in Journal of Constructional Steel Research 64 (2008) 971-98 